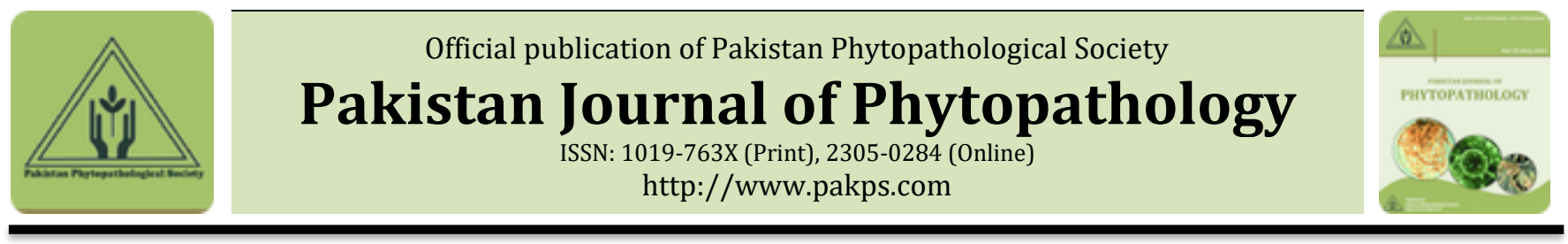

\title{
CONSERVATION OF CEREALFUNGI FOLLOWING DIFFERENT METHODS OF PRESERVATION FOR LONG TERMS
}

\author{
Nachaat Sakr \\ Department of Agriculture, Syrian Atomic Energy Commission, Damascus, P.O. Box 6091, Syria.
}

A B S T R A C T

Preservation of soil- and air-borne phytopathogenic fungi for extent durations of time is crucial so that analyses can be followed up any moment. The goal of the present research was to analyze storage methodologies in maintaining field isolates of Fusarium head blight (FHB), spot blotch (SB) and common root rot (CRR) diseases. Cereal fungal isolates were stored at four independent storage experiments (1) filter paper disks carrying fungal mycelium at $4^{\circ} \mathrm{C}$, (2) fungal suspension at ambient temperature, (3) fungal suspension at $4^{\circ} \mathrm{C}$ and (4) mycelial cultures on Petri-dishes with potato dextrose agar by freezing at $-16^{\circ} \mathrm{C}$. The survival, absence of microbial contamination and morphological constancy of cultures were tested in periods ranging from 1 to 60 months. The isolates were recovered from the four preservation treatments having +\% survival and maintaining their purity and morphological stability at each time point. Neither used storage technique, time in storage nor taxonomic classification was associated with a lack of viability, microbial contamination or morphology alternation. As far as we know, the present work is the first report highlighting the possibility of conservation for FHB, SB and CRR causal agents using filter paper disks stored in cold water for three years, fungal suspension at ambient temperature for 3 years, fungal suspension at $4^{\circ} \mathrm{C}$ in cold water and mycelial cultures by freezing for 5 years.

Keywords: cereal fungi, freezing, viability, water storage.

\section{INTRODUCTION}

The storage and keeping of phytopathogenic fungi in a viable yet constant situation for extent periods has always been crucial. Strains of these fungal pathogens can assist as standard for distinguishing of quarantine taxonomies. Such isolates are also essential for assessing disease resistance and for plant breeding strategies (Abd-Elsalam et al., 2010). Continual sub-culture is the most common method of fungal isolate preservation in isolate collections but is not suitable for prolonged preservation because it is taking a lot time and vulnerable to contamination (Holden and Smith, 1992). Over the years, several methods for the storage of fungal cultures have been

Submitted: August 17, 2020

Revised: December 07, 2020

Accepted for Publication: December 08, 2020

* Corresponding Author:

Email: ascientific@aec.org.sy

(C) 2017 Pak. J. Phytopathol. All rights reserved. assessed in order to reduce theses disadvantages, even though results depend on the fungus group in question. Methods to date are based on lyophilization, cryopreservation, sterile water, silica gel, sand, and freezing (reviewed in Abd-Elsalam et al., 2010). No singular method has been carried out effectively to all fungi due to the particular characteristics of each species.

Water storage method, described seventy years ago by Castellani, in addition to being simple and economically practical for small laboratories yields acceptable results for the keeping of most species of fungal pathogens. The temperature applied in water preservation method is varying, from $4^{\circ} \mathrm{C}$ to ambient temperature (McGinis et al., 1974; Dioigo et al., 2005; Eliot, 2005; Bormaan et aI., 2006; Bueno et aI., 2006; Guimaraes et al., 20I4; Roy et al., 20I4). In addition, fungal cultures can be kept frozen for long periods of time at $-20^{\circ} \mathrm{C}$ in standard freezers (readily available in almost mycology laboratories) to $-95^{\circ} \mathrm{C}$ by deep 
freezing to maintain viability. Unfortunately, the mechanical deep freezers that can store cultures at $-70^{\circ} \mathrm{C}$ or $-80^{\circ} \mathrm{C}$ are costly to buy, and depend on a constant feeding of electricity, or on a gasholder back-up method. Fusarium head blight (FHB), provoked by different Fusarium species and spot blotch (SB) and common root rot (CRR) caused by Cochliobolus sativus are consistently ones of the most important diseases of cereals worldwide (Agrios, 2004). However, a rarity of studies is available regarding the preservation in stable conditions for 10 years in silica gel, lyophilization and soil for some FHB species (Dhingara and Sinclair, 1985; WindeIs et al., 1993; Milosevic et aI., 2007), and for 2 years in sand and silica gel for SB causal agents (Arabi et al., 2007). Recently, FHB, SB and CRR isolates were stored in a constant status in the absence of any morphological changes and the microbial contamination of fungl culture can be reduced by freezing the culture at about $16^{\circ} \mathrm{C}$ up to 36 months (Sakr, 2018, 2019a). In addition, these stored FHB isolates in cold water or by freezing were used successfully in resistance and pathogenic studies in both barley- and wheat-FHB pathosystems (Sakr, 2019b, 2020a,b), indicating the importance of these storage methodologies in preserving fungal cultures in viable conditions (Sakr, 2018, 2019a). Thus, the maintaining of FHB, SB and CRR cultures in cold water or by freezing at $-16^{\circ} \mathrm{C}$ for extended periods is required to ensure the viability of these storage methods. So far, studies with water method for long time preservation of cultures at ambient temperature to keep FHB, SB and CRR causative agents have not been reported. Furthermore, using mycelia submerged cultures on filter paper disks is considered as a back-up strategy to enhance the chances of keeping both survival and morphological constancy for extent periods (Roy et al., 2014). Thus, there is a need to explore these easy, low cost and simple procedures in water storage at different temperatures and by freezing adequate in small mycological laboratories where the lyophilization and cryopreservation facilities are not necessarily available. The present study evaluates the viability, purity and morphological stability for several fungal cultures of five important cereal pathogens causing FHB, SB and CRR diseases at four independent experiments (1) filter paper disks carrying fungal mycelium at $4^{\circ} \mathrm{C}$ for three years, (2) fungal suspension at ambient temperature for three years, (3) fungal suspension at $4^{\circ} \mathrm{C}$ and (4) PDA plates containing culture can be stored upto five years at $-16^{\circ} \mathrm{C}$.

\section{MATERIALS AND METHODS}

Fungal isolates: Seventy fungal cultures sampled from naturally infected wheat and barley plants in different regions of Syria at the 2015 growing season of sixteen isolates from four specious of Fusarium head blight, Cochliobolus sativus causing spot blotch (32) and common root rot (22) were used. Recently, the 16 fungal isolates were molecularly analyzed by random amplified polymorphic DNA (Sakr, unpublished data).

Storage of filter paper disks carrying fungal mycelium in cold water (the first experiment)

The 70 fungal cultures were multiplied individually in Petri plates filled with $20 \mathrm{ml}$ of potato dextrose agar (PDA) over 5-mm filter paper disks placed alongside the culture for 10 days at $22 \pm 1^{\circ} \mathrm{C}$ under darkness to permit mycelial overgrew the disks. Then the filter paper disks were carefully and aseptically removed, and placed into sterile glass ampoules containing $8.0 \mathrm{ml}$ of sterile distilled water. All ampoules were hermetically sealed and tightly wrapped with Parafilm strips. Finally, all ampoules were stored at $4^{\circ} \mathrm{C}$.

For revival of the fungi, one culture laden filter paper disk was inoculated over fresh PDA Petri plates in an aseptic chamber and then incubated for 10 days for the fungal growth to be initiated. Viability tests were evaluated periodically after $3,6,9,12,15,18,21,24,27$, 30,33 and 36 months.

Preservation in sterile distilled water at ambient

temperature (the second experiment)

Ten fungal isolates of the five tested species, out of the 70 tested cultures, were chosen on the basis of morphological (mycelial growth rate, color, etc.) characteristics. The fungal suspension composing of spores and fragments of hyphae was harvested in softly flooding the cultures with $10 \mathrm{ml}$ of sterile distilled water on the aerial growth of actively growing colony in PDA Petri plates using a micropipette. The resultant suspension was aseptically withdrawn and transferred to sterile glass ampoules, which were hermetically closed and tightly wrapped with $2 \mathrm{~cm}$ Parafilm strips to prevent dehydration. The suspension was kept at ambient temperature i.e., $22 \pm 2{ }^{\circ} \mathrm{C}$.

For survival of cultures during periods from 1 up to 36 months, $100 \mu \mathrm{L}$ of fungal suspension was removed with a micropipette from sterile sealed glass ampoules under aseptic conditions. Fungal samples were grown in PDA Petri plates with and kept under continuous darkness for 10 days at $22 \pm 1^{\circ} \mathrm{C}$ to allow mycelial growth. 
Preservation in cold sterile distilled water (the third experiment)

For 70 isolates, the spores and fractions of hyphae were removed by softly scraping the airy growth with a pipette, and the resultant suspension was withdrawn and transferred to a sterile glass ampoules. The top of the ampoule was tightened to inhibit water evaporation. Then, sterile glass ampoules were kept at $4^{\circ} \mathrm{C}$ in two experiments initiated at two different dates.

After maintenance over 18 and 60 months, $300 \mu \mathrm{L}$ of fungal suspension were grown in PDA Petri plates and kept in conditions the above-mentioned conditions to permit mycelial growth.

Preservation by freezing at $-16^{\circ} \mathrm{C}$ (the fourth experiment) The samples of PDA Petri plates including fungal cultures attaining appropriate growth for 70 isolates were frozen at $-16^{\circ} \mathrm{C}$ in two experiments initiated at two different dates. After storage for up 18 and 60 months, isolates were thawed at $4^{\circ} \mathrm{C}$ for 24 hours. Five $5-\mathrm{mm}$ agar plugs were cut from the margin for each isolate. Then, they were placed onto fresh media and kept under the above-mentioned conditions to permit mycelial growth. Samples showing revival of at least one out of five agar plugs were assessed viable.

For the four preservation treatments in independent experiments, survived cultures were tested for morphological observation (agreement of sporulation, colony, texture, color, diameter, topography features with the previously known identification) and contamination by bacteria or other fungi.

\section{STATISTICAL ANALYSES}

Data were performed using DSAASTAT add-in version 2011. For each isolate, treatment means among storage times and storage methods were compared using Fisher's LSD test at $\mathrm{P}>0.05$.

\section{RESULTS}

It became evident from the findings of four independent experiments (Tables 1 to 3 ) that all tested isolates grew with $100 \%$ revival when sub-cultured on PDA and incubated at $22^{\circ} \mathrm{C}$ for 10 days. There were no significant differences at $\mathrm{P}>0.05$ among storage times and storage methods for each isolate over the four experiments. None of the revived cultures were found to be contaminated by bacteria or other fungi (Figures 1 to 3 ). In general the isolates kept their separately distinguished morphological colony features.

\section{DISCUSSION}

The extended outstanding topic of "living specimen" patterns for fungi will be resolved when it is proven that the life, properties and features of authentic cultures can be maintained (Smith and Onions, 1983; Nakasone et al., 2004). Fungi are highly variable eukaryotic organisms with a slow growth velocity in culture media compared with most of the bacteria. Also, colonial preservation has been harmed probably with the contamination by bacteria or other fungi (Diogo et al., 2005; Guimaraes et al., 2014). The available methods for the mycology collection storage are work-demanding, costly and inefficient most of the times. The development of novel forms of fungal maintenance for extended period should be sought, especially in small facilities to meet individual needs and limitations (Diogo et al., 2005; Abd-Elsalam et al., 2010; Guimaraes et al., 2014). Although the two procedures, cryopreservation and lyophilization, have been widely used for long term preservation, they are not necessarily available in all mycological laboratories (Borman et al., 2006).

A decision-based key for choosing best storage methods suited for fungal cultures has been developed by Ryan et al., (2000). A checking of this key related to the five cereal fungal species involved in this study (Fusarium culmorum, F. verticillioides, F. solani, F. equiseti and Cochliobolus sativus) clarifies the availability in determining which preservation method to use for these species. The analyzed fungi easily produce asexual spores in culture and do not have motile spores (Agrios, 2004), thus storage in water is recommended as economically, effectively and appropriate preservation technique, among the other available methods (Ryan et al., 2000; Sakr, 2018, 2019).

Viability of fungal cells has been noted as the most fundamental physiological state in mycological studies (Ryan et al., 2000; Abd-Elsalamet al., 2010). In the present work, each fungal isolate was assessed viable if the fungal cultures did grow in the absence of microbial contamination at the same as that of the authentic culture and if the morphological characteristics of the colony corresponded the fungal distinguishing certified for each isolate. The conservation of mycelium for 70 fungal cultures in the four tested independent experiments (filter paper disks stored in cold water, fungal suspension at ambient temperature, fungal suspension at $4^{\circ} \mathrm{C}$ in cold water and mycelial cultures by freezing) assured a total viability for the tested periods at each time point. Our findings are in parallel with these found by Abd-Elsalam et al., (2010) in which they 
observed that long term water and freezing storage methods incorporating mycelia submerged cultures, spores of fungi and factions of mycelium hyphae had high revival proportion. High viability evaluations were found for plant pathogen cultures kept in water at ambient temperature, cold water and by freezing (Legard and Chandler, 2000; Elliott, 2005; Bueno et al., 2006; Roy et al., 2014). Indeed, Sakr (2018, 2019a) found that the viability of the same fungal isolates was $+\%$ for 3 years using fungal suspension kept in cold water and by freezing of fungal cultures.

Selection of good sporulating cultures: (a) over filter paper disks placed alongside the culture, (b) for preparing fungal suspensions kept at $4^{\circ} \mathrm{C}$ or ambient temperature $\left(22 \pm 2^{\circ} \mathrm{C}\right)$ and (c) kept by freezing at $16^{\circ} \mathrm{C}$ was the most crucial factor affecting revival of fungal pathogens in water or by freezing during our investigation. Our findings appear to assist Bunse and Steigleder's supposition (1991), since we observed the highest re-growth evaluations for frozen $F$. culmorum, F. verticillioides, F. solani, F. equiseti and Cochliobolus sativus isolates which produce abundant spores. This hypothesis can explain the better results when freezing agar was utilized as growth medium, because freezing agar is known to enhance the output of fungal spores (Bunse and Steigleder, 1991). In this research, the techniques used to obtain water stored fungal isolates can be performed several times, using always the same glass ampoule, until total use of filter paper disks and fungal suspension. Moreover, space occupied by the whole set of glass ampoules is minimal. Furthermore, the samples of PDA Petri plates including fungal cultures attaining appropriate growth can easily be stored and transported. Neither used storage technique, time in storage nor taxonomic classification was associated with a lack of viability, microbial contamination or morphology alternation.

No visible alternations in morphological characteristics, or contamination by bacteria or other fungi which damage the storage of plant pathogen cultures were observed in the recovered cultures for the four used techniques. Maintaining in water and by freezing did not seem to influence obvious morphological cultural faeatures of the pathogen of Poaceae species Gaeumannomyces graminis var. graminis (Elliott, 2005) and strawberry pathogens (Legard and Chandler, 2000), and the same used 70 fungal isolates in this research kept as a fungal suspension in sterile distilled water at $4^{\circ} \mathrm{C}$ and by freezing of fungal cultures at $-16^{\circ} \mathrm{C}$ (Sakr, 2018, 2019a). On the other hand, Holden and Smith (1992) described problems of contamination in collections of fungi stored with the continuous subculturing method in PDA due to mites or other causes.

Longevity of water-stored cultures may be more or less efficient for an individual species or genus followed by its optimal storage condition. Regarding grapevine pathogenic fungi of genus Botryosphaeria, Baskarathevan et al., (2009) observed a failure in maintaining mycelium plugs in water at room temperature. Either the greater respiratory activity of fungal species caused by higher temperature or the influence of day/night regular fluctuations for ambient temperature suppressed the cultural recovery. However, highly growth rates for revived isolates were shown in treatments at $4 \stackrel{\circ}{ } \mathrm{C}$ (Baskarathevan et al., 2009). Also, cultures of medical species and 12 potentially toxigenic species of the genera Aspergillus and Penicillium were viable after stored in cold water (Diogoet al., 2005; Guimaraes et al., 2014). Notwithstanding, preservation of G. graminis var. graminisat ambient temperature was adequate for recovery due to the semitropical origin of this fungal species, and the worst treatments were in a cold water (Elliott, 2005). A wide range of fungi including human and plant pathogens retained viability by storage at room temperature as observed for 470 isolates of filamentous fungi, actinomycetes and yeasts belonging to 147 species from sixty six genera (McGinis et aI., 1974), while five hundred and ninety four isolates from one hundred and sixty species (de Capri1es et al., 1989), forty five species including one hundred and seventy nine isolates (Bormanet al., 2006) and two pathogenic fungi of rubber: Corynespora cassiicola and Phytophthora meadii (Roy et al., 2014). More interesting, survival of soil-borne phytopathogenic species of the genera Fusarium, Macrophomina, Rhizoctonia and Sclerotium was achieved by water storage at $5^{\circ} \mathrm{C}$ and $28^{\circ} \mathrm{C}$ (Buenoet $a l ., 2006)$. It seems that refrigeration or keeping at ambient temperature enhances survival of stored water-cultures at $4^{\circ} \mathrm{C}$ or $22 \pm 2^{\circ} \mathrm{C}$ of genera Fusarium and Cochliobolus used in the present study as observed previously by Sakr $(2018,2019$ a). 
Table 1. Viability (\%) of 70 water-stored cultures at $4^{\circ} \mathrm{Cby}$ two methods: filter paper disks containing mycelia and fungal suspension for five cereal phytopathogenic species (Fusarium culmorum, F. verticillioides, F. solani, $F$. equiseti and Cochliobolus sativus) for 36 months (first experiment)

\begin{tabular}{|c|c|c|c|c|c|c|c|c|c|c|c|c|c|c|c|c|c|c|c|c|c|c|c|c|c|}
\hline \multirow{3}{*}{$\begin{array}{c}\text { Fungal } \\
\text { isolates } \\
\text { (identification) }\end{array}$} & \multicolumn{12}{|c|}{ Preservation method } & \multirow{3}{*}{$\begin{array}{c}\text { Fungal } \\
\text { isolates } \\
\text { (identification }\end{array}$} & \multicolumn{12}{|c|}{ Preservation method } \\
\hline & \multicolumn{12}{|c|}{ Filter paper disks } & & \multicolumn{12}{|c|}{ Filter paper disks } \\
\hline & \multicolumn{12}{|c|}{ Periods in months } & & \multicolumn{12}{|c|}{ Periods in months } \\
\hline $\mathrm{F} 1(F c)$ & & & & & & & $+a$ & & & & & & C.S. 59 (SP) & & & & & & & $+a$ & & & & & \\
\hline $\mathrm{F} 2(F c)$ & & & & & & & $+a$ & & & & & & C.S. 17 (SP) & & & & & & & $+a$ & & & & & \\
\hline $\mathrm{F} 28(F c)$ & & & & & & & $+a$ & & & & & & C.S. 21 (SP) & & & & & & & $+a$ & & & & & \\
\hline $\mathrm{F} 30(F c)$ & & & & & & & $+a$ & & & & & & C.S. 89 (SP) & & & & & & & $+a$ & & & & & \\
\hline F7 $(F s)$ & & & & & & & $+a$ & & & & & & C.S. 53 (SP) & & & & & & & $+a$ & & & & & \\
\hline F20 $(F s)$ & & & & & & & $+a$ & & & & & & C.S. 86 (SP) & & & & & & & $+a$ & & & & & \\
\hline F26 $(F s)$ & & & & & & & $+a$ & & & & & & C.S. 74 (SP) & & & & & & & $+a$ & & & & & \\
\hline $\mathrm{F} 15(F v)$ & & & & & & & $+a$ & & & & & & C.S. 63 (SP) & & & & & & & $+a$ & & & & & \\
\hline $\mathrm{F} 16(F v)$ & & & & & & & $+\mathrm{a}$ & & & & & & C.S. 55 (SP) & & & & & & & $+\mathrm{a}$ & & & & & \\
\hline $\mathrm{F} 21(F v)$ & & & & & & & $+a$ & & & & & & C.S. 41 (CRR) & & & & & & & $+a$ & & & & & \\
\hline F27 $(F v)$ & & & & & & & $+a$ & & & & & & C.S. 50 (CRR) & & & & & & & $+a$ & & & & & \\
\hline $\mathrm{F} 43(\mathrm{Fe})$ & & & & & & & $+a$ & & & & & & C.S. 37 (CRR) & & & & & & & $+a$ & & & & & \\
\hline C.S. 14 (SP) & & & & & & & $+a$ & & & & & & C.S. 36 (CRR) & & & & & & & $+a$ & & & & & \\
\hline C.S. 27 (SP) & & & & & & & $+a$ & & & & & & C.S. 24 (CRR) & & & & & & & $+a$ & & & & & \\
\hline C.S. 32 (SP) & & & & & & & $+a$ & & & & & & C.S. 23 (CRR) & & & & & & & $+a$ & & & & & \\
\hline C.S. 30 (SP) & & & & & & & $+a$ & & & & & & C.S. 25 (CRR) & & & & & & & $+a$ & & & & & \\
\hline C.S. 93 (SP) & & & & & & & $+a$ & & & & & & C.S. 46 (CRR) & & & & & & & $+a$ & & & & & \\
\hline C.S. 16 (SP) & & & & & & & $+a$ & & & & & & C.S. 47 (CRR) & & & & & & & $+a$ & & & & & \\
\hline C.S. 87 (SP) & & & & & & & $+a$ & & & & & & C.S. 51 (CRR) & & & & & & & $+a$ & & & & & \\
\hline C.S. 83 (SP) & & & & & & & $+a$ & & & & & & C.S. 8 (CRR) & & & & & & & $+a$ & & & & & \\
\hline C.S. 45 (SP) & & & & & & & $+a$ & & & & & & C.S. 40 (CRR) & & & & & & & $+a$ & & & & & \\
\hline C.S. 11 (SP) & & & & & & & $+a$ & & & & & & C.S. 1 (CRR) & & & & & & & $+a$ & & & & & \\
\hline C.S. 9 (SP) & & & & & & & $+\mathrm{a}$ & & & & & & C.S. 10 (CRR) & & & & & & & $+\mathrm{a}$ & & & & & \\
\hline C.S. 15 (SP) & & & & & & & $+a$ & & & & & & C.S. 5 (CRR) & & & & & & & $+a$ & & & & & \\
\hline C.S. 26 (SP) & & & & & & & $+a$ & & & & & & C.S. 28 (CRR) & & & & & & & $+a$ & & & & & \\
\hline
\end{tabular}

Fc: Fusarium culmorum, Fs: F. solani, Fv: F. verticillioides, Fe: F. equiseti, SB: Spot blotch and CRR: common root rot,$+=$ mycelial growth expressed by $100 \%$. According to the Fisher's LSD test, means among the storage times in each storage method within a row followed by the same letter are not significantly different at $\mathrm{P}>0.05$ for each isolate. 
Table 2. Viability (\%) of 16 water-stored cultures at ambient temperature $\left(22 \pm 2^{\circ} \mathrm{C}\right)$ five cereal phytopathogenic species (Fusarium culmorum, F. verticillioides, F. solani, F. equiseti and Cochliobolus sativus) for 36 months (second experiment)

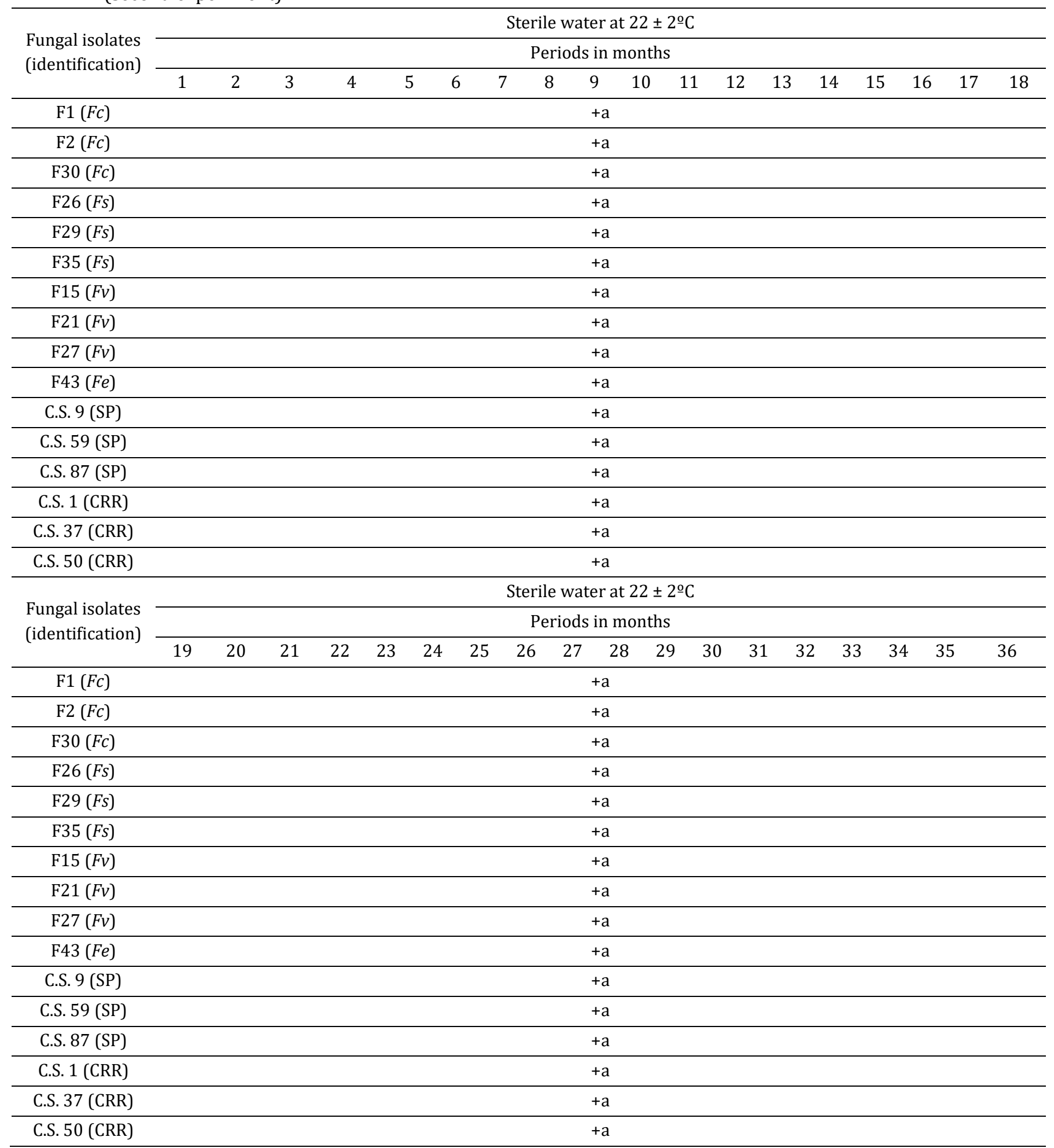

FC: Fusarium culmorum, Fs: F. solani, Fv: F. verticillioides, Fe: F. equiseti, SB: Spot blotch and CRR: common root rot, + = mycelial growth expressed by $100 \%$. According to the Fisher's LSD test, means among the storage times in each storage method within a row followed by the same letter are not significantly different at $\mathrm{P}>0.05$ for each isolate. 
Table 3. Viability (\%) of 70 water-stored at $4^{\circ}$ Cand frozen cultures at $-16^{\circ}$ Cof five cereal phytopathogenic species (Fusariumculmorum, F. verticillioides, F. solani, F. equiseti and Cochliobolus sativus) for 18 and 60 months (third and fourth experiment)

\begin{tabular}{|c|c|c|c|c|c|}
\hline \multirow{3}{*}{$\begin{array}{c}\text { Fungal } \\
\text { Isolates(identification) }\end{array}$} & \multicolumn{2}{|c|}{ Preservation methods } & \multirow{3}{*}{$\begin{array}{c}\text { Fungal } \\
\text { Isolates(identification) }\end{array}$} & \multicolumn{2}{|c|}{ Preservation methods } \\
\hline & sterile water & freezing & & sterile water & freezing \\
\hline & 60 & $18 \quad 60$ & & $18 \quad 60$ & $18 \quad 60$ \\
\hline $\mathrm{F} 1(F c)$ & $+\mathrm{a}^{\mathrm{a}}$ & $+\mathrm{a}^{\mathrm{a}}$ & C.S. 59 (SP) & $+a^{a}$ & $+\mathrm{a}^{\mathrm{a}}$ \\
\hline $\mathrm{F} 2(F c)$ & $+\mathrm{a}^{\mathrm{a}}$ & $+\mathrm{a}^{\mathrm{a}}$ & C.S. 17 (SP) & $+\mathrm{a}^{\mathrm{a}}$ & $+\mathrm{a}^{\mathrm{a}}$ \\
\hline $\mathrm{F} 3(F c)$ & $+a^{a}$ & $+\mathrm{a}^{\mathrm{a}}$ & C.S. 34 (SP) & $+\mathrm{a}^{\mathrm{a}}$ & $+\mathrm{a}^{\mathrm{a}}$ \\
\hline F28 $(F c)$ & $+\mathrm{a}^{\mathrm{a}}$ & $+\mathrm{a}^{\mathrm{a}}$ & C.S. 21 (SP) & $+\mathrm{a}^{\mathrm{a}}$ & $+\mathrm{a}^{\mathrm{a}}$ \\
\hline F30 $(F c)$ & $+\mathrm{a}^{\mathrm{a}}$ & $+\mathrm{a}^{\mathrm{a}}$ & C.S. 89 (SP) & $+\mathrm{a}^{\mathrm{a}}$ & $+\mathrm{a}^{\mathrm{a}}$ \\
\hline F7 (Fs) & $+a^{a}$ & $+\mathrm{a}^{\mathrm{a}}$ & C.S. 53 (SP) & $+\mathrm{a}^{\mathrm{a}}$ & $+\mathrm{a}^{\mathrm{a}}$ \\
\hline F31 $(F s)$ & $+\mathrm{a}^{\mathrm{a}}$ & $+\mathrm{a}^{\mathrm{a}}$ & C.S. 86 (SP) & $+\mathrm{a}^{\mathrm{a}}$ & $+\mathrm{a}^{\mathrm{a}}$ \\
\hline F35 $(F s)$ & $+a^{a}$ & $+a^{a}$ & C.S. 74 (SP) & $+a^{a}$ & $+\mathrm{a}^{\mathrm{a}}$ \\
\hline $\mathrm{F} 20(F s)$ & $+a^{a}$ & $+\mathrm{a}^{\mathrm{a}}$ & C.S. 49 (SP) & $+\mathrm{a}^{\mathrm{a}}$ & $+\mathrm{a}^{\mathrm{a}}$ \\
\hline $\mathrm{F} 26(F s)$ & $+\mathrm{a}^{\mathrm{a}}$ & $+\mathrm{a}^{\mathrm{a}}$ & C.S. 9 (SP) & $+\mathrm{a}^{\mathrm{a}}$ & $+\mathrm{a}^{\mathrm{a}}$ \\
\hline F29 $(F s)$ & $+\mathrm{a}^{\mathrm{a}}$ & $+\mathrm{a}^{\mathrm{a}}$ & C.S. 12 (SP) & $+\mathrm{a}^{\mathrm{a}}$ & $+\mathrm{a}^{\mathrm{a}}$ \\
\hline $\mathrm{F} 15(F v)$ & $+a^{a}$ & $+\mathrm{a}^{\mathrm{a}}$ & C.S. 63 (SP) & $+\mathrm{a}^{\mathrm{a}}$ & $+\mathrm{a}^{\mathrm{a}}$ \\
\hline $\mathrm{F} 16(F V)$ & $+a^{a}$ & $+\mathrm{a}^{\mathrm{a}}$ & C.S. 55 (SP) & $+\mathrm{a}^{\mathrm{a}}$ & $+\mathrm{a}^{\mathrm{a}}$ \\
\hline $\mathrm{F} 21(F v)$ & $+\mathrm{a}^{\mathrm{a}}$ & $+\mathrm{a}^{\mathrm{a}}$ & C.S. 41 (CRR) & $+\mathrm{a}^{\mathrm{a}}$ & $+\mathrm{a}^{\mathrm{a}}$ \\
\hline F27 $(F v)$ & $+a^{a}$ & $+\mathrm{a}^{\mathrm{a}}$ & C.S. 50 (CRR) & $+\mathrm{a}^{\mathrm{a}}$ & $+\mathrm{a}^{\mathrm{a}}$ \\
\hline $\mathrm{F} 43(\mathrm{Fe})$ & $+\mathrm{a}^{\mathrm{a}}$ & $+a^{a}$ & C.S. 37 (CRR) & $+a^{a}$ & $+\mathrm{a}^{\mathrm{a}}$ \\
\hline C.S. 14 (SP) & $+\mathrm{a}^{\mathrm{a}}$ & $+\mathrm{a}^{\mathrm{a}}$ & C.S. 36 (CRR) & $+\mathrm{a}^{\mathrm{a}}$ & $+\mathrm{a}^{\mathrm{a}}$ \\
\hline C.S. 27 (SP) & $+a^{a}$ & $+\mathrm{a}^{\mathrm{a}}$ & C.S. 24 (CRR) & $+\mathrm{a}^{\mathrm{a}}$ & $+\mathrm{a}^{\mathrm{a}}$ \\
\hline C.S. 32 (SP) & $+a^{a}$ & $+\mathrm{a}^{\mathrm{a}}$ & C.S. 23 (CRR) & $+\mathrm{a}^{\mathrm{a}}$ & $+\mathrm{a}^{\mathrm{a}}$ \\
\hline C.S. 92 (SP) & $+\mathrm{a}^{\mathrm{a}}$ & $+\mathrm{a}^{\mathrm{a}}$ & C.S. 44 (CRR) & $+\mathrm{a}^{\mathrm{a}}$ & $+\mathrm{a}^{\mathrm{a}}$ \\
\hline C.S. 20 (SP) & $+\mathrm{a}^{\mathrm{a}}$ & $+a^{a}$ & C.S. 48 (CRR) & $+a^{a}$ & $+\mathrm{a}^{\mathrm{a}}$ \\
\hline C.S. 2 (SP) & $+a^{a}$ & $+a^{a}$ & C.S. 52 (CRR) & $+a^{a}$ & $+\mathrm{a}^{\mathrm{a}}$ \\
\hline C.S. 80 (SP) & $+\mathrm{a}^{\mathrm{a}}$ & $+\mathrm{a}^{\mathrm{a}}$ & C.S. 13(CRR) & $+\mathrm{a}^{\mathrm{a}}$ & $+\mathrm{a}^{\mathrm{a}}$ \\
\hline C.S. 7 (SP) & $+\mathrm{a}^{\mathrm{a}}$ & $+\mathrm{a}^{\mathrm{a}}$ & C.S. 6 (CRR) & $+\mathrm{a}^{\mathrm{a}}$ & $+\mathrm{a}^{\mathrm{a}}$ \\
\hline C.S. 18 (SP) & $+\mathrm{a}^{\mathrm{a}}$ & $+\mathrm{a}^{\mathrm{a}}$ & C.S. 38 (CRR) & $+\mathrm{a}^{\mathrm{a}}$ & $+\mathrm{a}^{\mathrm{a}}$ \\
\hline C.S. 30 (SP) & $+a^{a}$ & $+\mathrm{a}^{\mathrm{a}}$ & C.S. 25 (CRR) & $+\mathrm{a}^{\mathrm{a}}$ & $+\mathrm{a}^{\mathrm{a}}$ \\
\hline C.S. 93 (SP) & $+\mathrm{a}^{\mathrm{a}}$ & $+\mathrm{a}^{\mathrm{a}}$ & C.S. 46 (CRR) & $+\mathrm{a}^{\mathrm{a}}$ & $+\mathrm{a}^{\mathrm{a}}$ \\
\hline C.S. 16 (SP) & $+a^{a}$ & $+\mathrm{a}^{\mathrm{a}}$ & C.S. 47 (CRR) & $+\mathrm{a}^{\mathrm{a}}$ & $+\mathrm{a}^{\mathrm{a}}$ \\
\hline C.S. 87 (SP) & $+\mathrm{a}^{\mathrm{a}}$ & $+\mathrm{a}^{\mathrm{a}}$ & C.S. 51 (CRR) & $+\mathrm{a}^{\mathrm{a}}$ & $+\mathrm{a}^{\mathrm{a}}$ \\
\hline C.S. 83 (SP) & $+\mathrm{a}^{\mathrm{a}}$ & $+\mathrm{a}^{\mathrm{a}}$ & C.S. 8 (CRR) & $+\mathrm{a}^{\mathrm{a}}$ & $+\mathrm{a}^{\mathrm{a}}$ \\
\hline C.S. 45 (SP) & $+\mathrm{a}^{\mathrm{a}}$ & $+\mathrm{a}^{\mathrm{a}}$ & C.S. 40 (CRR) & $+\mathrm{a}^{\mathrm{a}}$ & $+\mathrm{a}^{\mathrm{a}}$ \\
\hline C.S. 11 (SP) & $+\mathrm{a}^{\mathrm{a}}$ & $+\mathrm{a}^{\mathrm{a}}$ & C.S. 1 (CRR) & $+\mathrm{a}^{\mathrm{a}}$ & $+\mathrm{a}^{\mathrm{a}}$ \\
\hline C.S. 9 (SP) & $+a^{a}$ & $+\mathrm{a}^{\mathrm{a}}$ & C.S. 10 (CRR) & $+\mathrm{a}^{\mathrm{a}}$ & $+\mathrm{a}^{\mathrm{a}}$ \\
\hline C.S. 15 (SP) & $+\mathrm{a}^{\mathrm{a}}$ & $+a^{a}$ & C.S. 5 (CRR) & $+\mathrm{a}^{\mathrm{a}}$ & $+\mathrm{a}^{\mathrm{a}}$ \\
\hline C.S. 26 (SP) & $+a^{a}$ & $+a^{a}$ & C.S. 28 (CRR) & $+\mathrm{a}^{\mathrm{a}}$ & $+\mathrm{a}^{\mathrm{a}}$ \\
\hline
\end{tabular}

FC: Fusarium culmorum, Fs: F. solani, Fv: F. verticillioides, Fe: F. equiseti, SB: Spot blotch and CRR: common root rot, + = mycelial growth expressed by $100 \%$. According to the Fisher's LSD test, means among the storage times in each storage method within a row followed by the same letter are not significantly different at $\mathrm{P}>0.05$ for each isolate. 
According to the Fisher's LSD test, means between the two storage methods (sterile water and freezing) between the two columns for each storage time followed by the same superscript letter are not significantly different at $\mathrm{P}>0.05$ for each isolate.

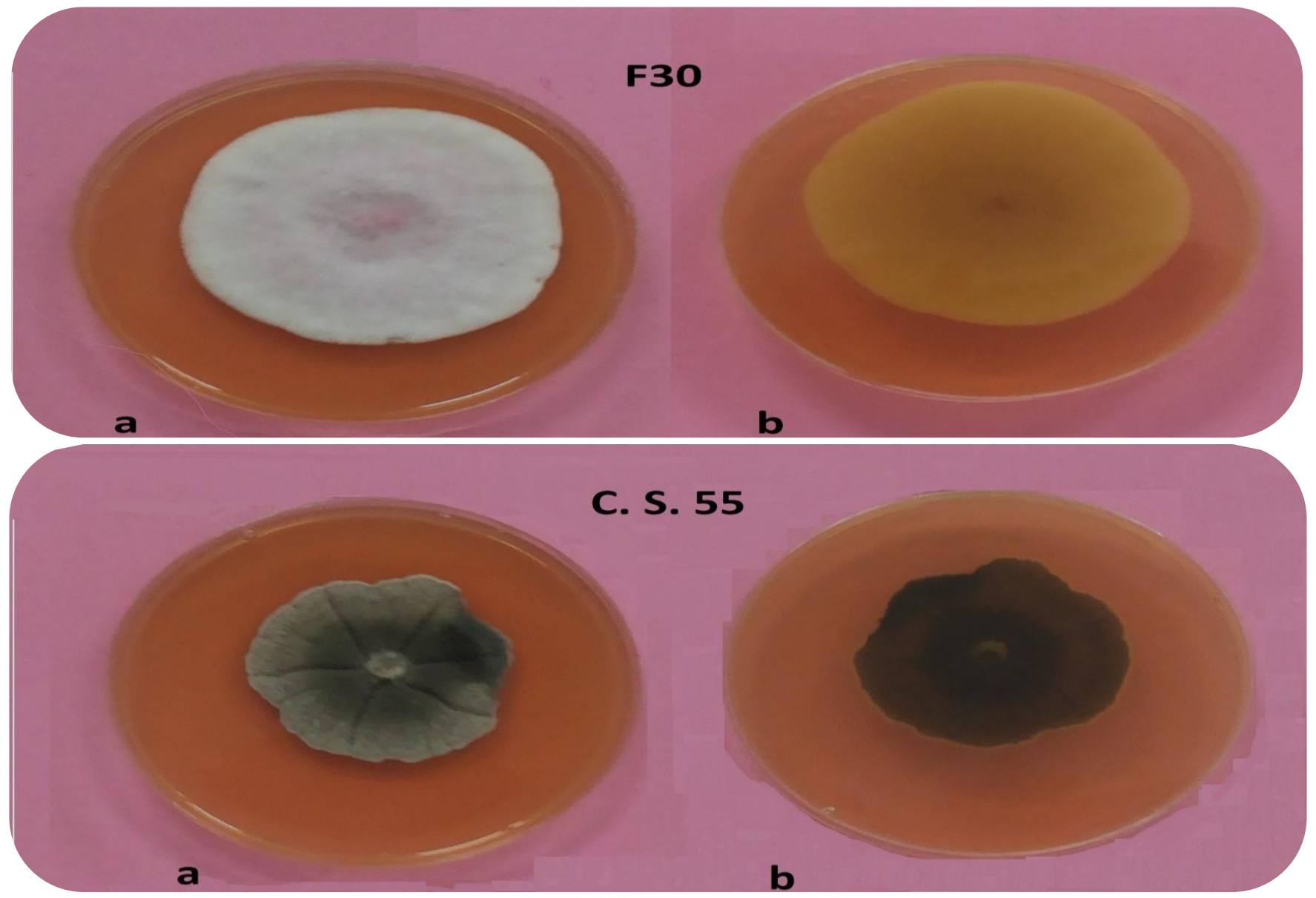

Figure 1. Revived fungal cultures of two isolates: F30 (Fusarium culmorum) and C.S. 55 (Cochliobolus sativus) onto fresh medium recovered from filter paper disks stored in sterile distilled water at $4^{\circ} \mathrm{C}$. (a) Cultivation of fungal cultures growing in the PDA Petri-dish. (b) The bottom of the PDA Petri-dish with filter paper disks covered by mycelium (first experiment)
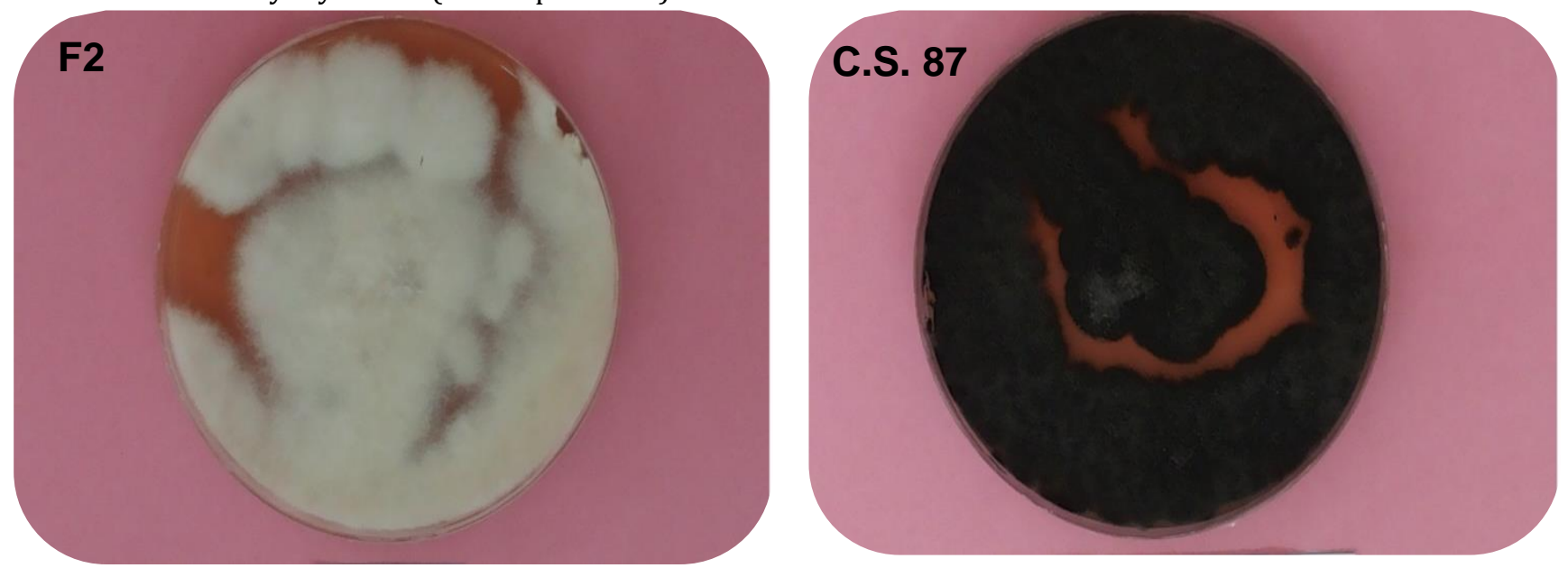

Figure 2. Revived fungal cultures of two isolates: F2 (Fusarium culmorum) and C.S. 87 (Cochliobolus sativus) onto fresh medium recovered from fungal suspension stored at ambient temperature $\left(22 \pm 2{ }^{\circ} \mathrm{C}\right)$ (second experiment) 


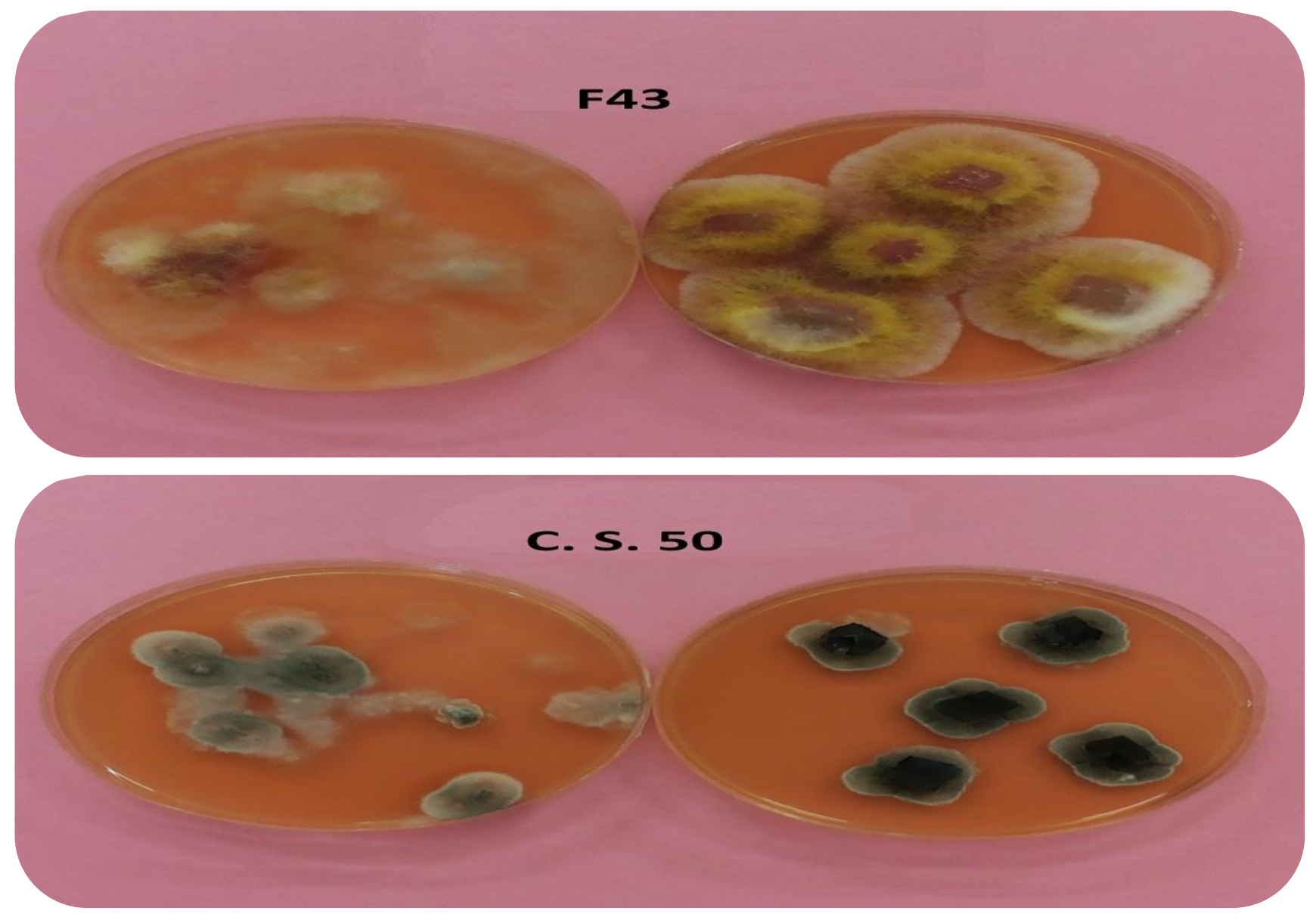

Figure 3. Revived fungal cultures of two isolates: F43 (Fusarium equiesti) and C.S. 50 (Cochliobolus sativus) onto fresh medium recovered from from cultures preserved in sterile distilled water at $4^{\circ} \mathrm{C}$ (left side) and freezing at $16^{\circ} \mathrm{C}$ (right side)

As far as we know, the present work is the first report highlighting the potential of conservation for FHB, SB and CRR fungi in a viable state using filter paper disks stored in cold water for three years, fungal suspension at ambient temperature for 3 years, fungal suspension at $4^{\circ} \mathrm{C}$ in cold water and mycelial cultures by freezing for 5 years. The presented four used techniques of preservation fungal isolates have the following - interests: (1) the risk of contamination with bacteria, other fungi or mites is eliminated, (2) the specimens can readily be maintained and transferred, (3) the morphology of the cultures was not changed so that these can be utilized directly as references or for illustration, and (4) all revived cultures were identical with the corresponding storage isolates about the macro- and microscopical characters of the cultures and fungus cells. It is argued that these easy, low cost and simple procedures were adequate in small mycological laboratories where the lyophilization and cryopreservation facilities are not necessary available.

\section{ACKNOWLEDGEMENTS}

The author would like to thank AEC of Syria for the financial support. The Associate Editor and anonymous Reviewers are thanked also for valuable comments on this paper.

\section{REFERENCES}

Abd-Elsalam, K. A., M. A. Yassin, M. A. Moslem, A. H. Bahkali, E. H. C. Mckenzie, S. L. Stephenson, L. Cai and K. D. Hyde. 2010. Culture collections, the new herbaria for fungal pathogens. Fungal Diversity, 45: 21-32.

Agrios, G. N. 2004. Plant pathology. Elsevier Academic, New Jersey, USA.

Arabi, M. I. E., M. Jawhar and A. Al-Daoude. 2007. Viability of Cochliobolussativuscultures after storage under different conditions. Journal of Plant Pathology, 89: 79-83.

Baskarathevan, J., M. V. Jaspers, E. E. Jones and H. J. Ridgway. 2009. Evaluation of different storage 
methods for rapid and cost-effective preservation of Botryosphaeria species. New Zealand Plant Protection, 62: 234-237.

Borman, A. M., A. Szekely, C. K. Campbell and E. M. Johnson. 2006. Evaluation of the viability of pathogenic filamentous fungi after prolonged storage in sterile water and review of recent published studies on storage methods. Mycopathologia, 161: 361-368.

Bueno, C. J., M. M. De. Q. Ambrosio and N. L. De. Souza. 2006. Storage of soilborne phytopathogenic fungi. Summa Phytopathologica, 32: 42-50.

Bunse, T and G. K. Steigleder. 1991. The preservation of fungal cultures by lyophilization. Mycoses, 34: 173176.

De Capriles, C. H., S. Mata and M. Middelveen. 1989. Preservation of fungi in water (Castellani): 20 years. Mycopathologia, 106: 73-79.

Dhingra O. D. and J. B. Sinclair. 1985. Basic Plant Pathology Methods. CRC Press, Florida, USA.

Diogo, H. C., A. Sarpieri and M. C. Pires. 2005. Fungi preservation in distilled water. Brazilian Annals of Dermatology, 80: 591-594.

Elliott, M. L. 2005. Survival, growth and pathogenicity of Gaeumannomyces graminis var. graminis with different methods of long term storage. Mycologia, 97: 901-907.

Guimaraes, L. C., A. P. Fernandes, S. M. Chalfoun and L. R. Batista. 2014. Methods to preserve potentially toxigenic fungi. Brazilian Journal of Microbiology, 4: 43-47.

Holden, A. N. G. and D. Smith. 1992. Effects of cryopreservation methods in liquid nitrogen on viability of Puccina abrupta var. partheniicola urediniospores. Mycological Research, 96: 473-476.

Hornby, D. and G. L. Bateman. 1998. Take-all disease of cereals: A Regional Perspective. CAB International, Wallingford, UK.

Legard, D. E. and C. K. Chandler. 2000. Cryopreservation of strawberry pathogen in mechanical ultra-low temperature freezer. HortScience, 35: 1357.

McGinnis, M. R., A. A. Padhye and L. Ajello. 1974. Storage of stock cultures of filamentous fungi, yeasts, and some aerobic Actinomycetes in sterile distilled water. Applied Microbiology, 28: 218-222.

Milosevic, M. B., S. S. Medic-Pap, M. V. Ignjatov and D. N. Petrovic, 2007.Lyophilization as a method for pathogens long term preservation. Matica Srpska Journal for Natural Sciences, 113: 203-210.

Nakasone, K. K., S. W. Peterson and S. C. Jong. 2004. Preservation and distribution of fungal cultures. In: Muller, G. M. (eds), Biodiversity of Fungi. Elsevier Academic Press, San Diego, USA.

Roy, C. B., P. Srinivas and C. K. Jacob. 2014. Relative efficacy of long-term storage methods on survival and virulence of Corynespora cassiicola and Phytophthora meadii pathogenic on rubber (Hevea brasiliensis). Rubber Science, 27: 202-214.

Ryan, M. J., D. Smith and P. Jeffries. 2000. A decision-based key to determine the most appropriate protocol for the preservation of fungi. World Journal of Microbiology and Biotechnology, 16: 183-186.

Sakr, N. 2018. Evaluation of two storage methods for fungal isolates of Fusarium sp. and Cochliobolu ssativus. Acta Phytopathologica et Entomologica Hungarica, 53: 11-18.

Sakr, N. 2019a. Long term storage for five important cereal phytopathogenic species. Pakistan Journal of Phytopathology, 31: 155-162.

Sakr N. 2019b. Variation in aggressiveness of Fusarium head blight species towards barley plants determined using three in vitro assays. Pakistan Journal of Phytopathology, 31:19-33.

Sakr, N. 2020a. Aggressiveness of Fusarium species causing head blight in barley landraces grown under Fertile Crescent conditions. Pakistan Journal of Phytopathology, 32: 41-52.

Sakr N. 2020b. Components of quantitative resistance to Fusarium head blight agents in durum and bread wheat plants grown under Mediterranean conditions. Archives of Phytopathology and Plant Protection, 53: 731-748.

Smith, D. and A. H. S. Onions. 1983. The Preservation and maintenance of living fungi. Commonwealth Mycological Institute, Kew, UK.

Windels, C. E., P. M. Burnes and T. Kommedahll. 1993. Fusarium species stored on silica gel and soil for ten years. Mycologia, 85: 21-23. 